\title{
TANINOS: UMA ABORDAGEM DA QUÍMICA À ECOLOGIA
}

\author{
Julio Marcelino Monteiro, Ulysses Paulino de Albuquerque* e Elcida de Lima Araújo \\ Departamento de Biologia, Área de Botânica, Universidade Federal Rural de Pernambuco, \\ Av. Dom Manoel de Medeiros, s/n, 52171-900 Recife - PE \\ Elba Lúcia Cavalcanti de Amorim \\ Departamento de Ciências Farmacêuticas, Centro de Ciências da Saúde, Universidade Federal de Pernambuco, \\ Av. Prof. Nelson Chaves, s/n, 50670-901 Recife - PE
}

Recebido em 31/3/04; aceito em 19/1/05; publicado na web em 13/4/05

\begin{abstract}
TANNINS: FROM CHEMISTRY TO ECOLOGY. Tannins are compounds of great interest in chemistry and ecology. They have various effects on food digestibility and the performance of animals. In this work, the chemistry, the biological activity and the ecology of tannins are examined. A brief discussion of several analytical methods for the determination of tannins is presented.
\end{abstract}

Keywords: tannins; colorimetric assay; biological activity.

\section{INTRODUÇÃOO}

Os compostos do metabolismo secundário vegetal ou metabolismo especial apresentam um amplo valor nas interações entre a planta e seu ecossistema exercendo, por ex., o papel de fagoinibidores contra herbívoros ou como agentes antimicrobianos ${ }^{1}$. Como metabólitos secundários, os taninos são compostos fenólicos de grande interesse econômico e ecológico. Apresentam solubilidade em água e peso molecular compreendido entre 500 e 3000 Dalton, possuindo a habilidade de formar complexos insolúveis em água com proteínas, gelatinas e alcalóides². Tais compostos são responsáveis pela adstringência de muitos frutos e produtos vegetais, devido à precipitação de glucoproteínas salivares, o que ocasiona a perda do poder lubrificante ${ }^{3}$.

A ligação entre taninos e proteínas ocorre, provavelmente, através de pontes de hidrogênio entre os grupos fenólicos dos taninos e determinados sítios das proteínas, emprestando uma duradoura estabilidade a estas substâncias. Para a formação destas ligações é necessário que o peso molecular dos taninos esteja compreendido entre limites bem definidos; se este é demasiadamente elevado, a molécula não pode se intercalar entre os espaços interfibrilares das proteínas ou macromoléculas; se é muito baixo, a molécula fenólica se intercala, mas não forma um número suficiente de ligações que assegure a estabilidade da combinação ${ }^{3}$. Os taninos têm sido alvo de diversos estudos, sendo que a maioria vem abordando interações ecológicas entre vegetais e herbívoros, visto que se têm sugerido que os teores de taninos podem diminuir a taxa de predação por se tornarem impalatáveis, afastando seus predadores naturais ${ }^{4-8}$. Pesquisas sobre atividade biológica dos taninos evidenciaram importante ação contra determinados microrganismos ${ }^{4}$, como agentes carcinogênicos e causadores de toxicidade hepática9 ${ }^{9}$. Estes últimos efeitos, sem dúvida, dependem da dose e do tipo de tanino ingerido. A ingestão de chá verde e de dietas ricas em frutas que contêm taninos, por ex., tem sido associada com atividade anticarcinogênica9. Além disso, podem agir como antiinflamatórios e cicatrizantes $^{2}$, e até como inibidores da transcriptase reversa em $\mathrm{HIV}^{10}$.

\footnotetext{
*e-mail: upa@ufrpe.br
}

Alguns trabalhos têm tratado do aspecto antinutricional de cultivares com altos teores de taninos e sua resistência a pragas ${ }^{11,12}$. Outros trabalhos têm avaliado a influência de diferentes variáveis nos teores de taninos em espécies de interesse econômico ${ }^{13,14}$. A sazonalidade tem sido apontada como um interessante fator para algumas espécies. Coletas realizadas com diferença de um ano demonstraram variação quantitativa entre taninos em espécies de Quercus $^{15}$. Essa variação também pode ser observada em diferentes partes de uma mesma planta. Por ex., em indivíduos de Stryphnodendron adstringens (Mart.) Coville, os teores de taninos nas cascas variaram de acordo com o local de origem da amostra ${ }^{13}$. Por sua vez, Caldeira e colaboradores ${ }^{14}$ não encontraram variação nos teores de tanino em Acacia mearnsii De Wild. em função da altura do ponto de coleta na planta em que a amostra foi obtida.

Muitas espécies produtoras de taninos são usadas na medicina popular para diferentes finalidades e poucos estudos têm avaliado o potencial medicinal de tais substâncias. Este artigo constitui-se em uma breve revisão sobre atividade biológica, química e ecologia de taninos, associando essas informações com problemas de pesquisa na área de plantas medicinais.

\section{Características químicas de taninos}

A palavra tanino é largamente usada, particularmente em literatura botânica, originalmente derivada do termo "tanante", implicando que o material vegetal produza couro a partir de peles ${ }^{16,17}$.

A maioria dos compostos fenólicos não é encontrada no estado livre na natureza, mas sob forma de ésteres ou de heterosídeos sendo, portanto, solúveis em água e em solventes orgânicos polares $^{2}$. Por serem fenólicos, os taninos são muito reativos quimicamente, formam pontes de hidrogênio, intra e intermoleculares. Um mol de taninos pode ligar-se a doze moles de proteínas; fundamentando-se nessa propriedade pode-se identificar taninos por teste de precipitação de gelatinas, por ex..,9,18,19. Estes compostos são facilmente oxidáveis, tanto através de enzimas vegetais específicas quanto por influência de metais, como cloreto férrico, o que ocasiona o escurecimento de suas soluções ${ }^{2}$.

Classicamente, segundo a estrutura química, os taninos são classificados em dois grupos: hidrolisáveis e condensados. Os taninos hidrolisáveis consistem de ésteres de ácidos gálicos e ácidos elágicos 
glicosilados, formados a partir do chiquimato ${ }^{6}$, onde os grupos hidroxila do açúcar são esterificados com os ácidos fenólicos ${ }^{19}$. Os taninos elágicos são muito mais freqüentes que os gálicos, e é provável que o sistema bifenílico do ácido hexaidroxidifenílico seja resultante da ligação oxidativa entre dois ácidos gálicos ${ }^{3}$.

Largamente encontrados no reino vegetal, os taninos condensados ou proantocianidinas são polímeros de flavan-3-ol e/ou flavan3,4-diol, produtos do metabolismo do fenilpropanol ${ }^{6,20-23}$. As proantocianidinas, assim denominadas provavelmente pelo fato de apresentarem pigmentos avermelhados da classe das antocianidinas, como cianidina e delfinidina ${ }^{2}$, apresentam uma rica diversidade estrutural, resultante de padrões de substituições entre unidades flavânicas, diversidade de posições entre suas ligações e a estereoquímica de seus compostos. Mello e Santos ${ }^{2}$ ressaltaram ainda que a ocorrência destes compostos é comum em angiospermas e gimnospermas, principalmente em plantas lenhosas.

Com a intenção de localizar a origem intracelular da síntese de taninos hidrolisáveis foram desenvolvidos, através de técnicas imunocitoquímicas, dois anticorpos que reconhecem como antígenos os compostos pentagaloilglucose e a enzima galoiltransferase, catalisadora de taninos hidrolisáveis ${ }^{24,25}$. Esta técnica foi empregada por apresentar uma alta especificidade e um grande poder de precisão, uma vez que os reagentes usualmente utilizados (como ex., $\mathrm{Fe}^{2+}, \mathrm{Fe}^{3+}$ ou molibdato) não apresentam distinção entre outros compostos fenólicos vegetais. Contrastando com a literatura vigente que prega a existência de "vacúolos tânicos", não foram encontrados tais compartimentos e sim regiões nos cloroplastos, nos amiloplastos, na parede celular e em espaços intercelulares que apresentaram locais de formação e deposição de taninos hidrolisáveis nas folhas de Quercus robus L. e Tellima grandiflora (Pursh.) Dough.

Considerando a proporção da ocorrência de taninos em famílias das Angiospermas arranjadas de acordo ao sistema de classificação de Cronquist, somente 4\% de 228 espécies testadas por Mole $^{26}$ foram positivas para taninos. Nas ordens Polygonales e Plumbaginales apenas uma única família de cada apresentou taninos, e em famílias de Caryophyllales tais compostos estavam ausentes. Nas Moraceae, os taninos estão presentes em quantidade insuficiente para precipitar proteínas. Mole ressalta ainda que, em comparação com as dicotiledôneas, as monocotiledôneas apresentam menos informações sobre taninos. Diante deste fato, é precipitada qualquer afirmação de que a perda destes compostos permanece como regra em decorrência do avanço evolutivo, como sugerem Santos e Blatt ${ }^{27}$.

\section{Determinação do teor de taninos}

Os taninos vegetais têm sido quantificados por diversos tipos de ensaios, como precipitação de metais ou proteínas e por métodos colorimétricos, sendo esses últimos mais comuns. Os métodos mais apropriados para determinação de taninos são os ensaios com precipitação de proteínas ${ }^{28,29}$. Alguns ensaios colorimétricos são usados para quantificar grupos de taninos específicos, muito embora estes métodos sejam amplamente usados para analisar taninos de uma maneira geral, como no caso de taninos hidrolisáveis; eles detectam somente grupos galoil e hexaidroxidifenóis (HHDP). Apesar destas críticas, alguns autores afirmam que não há método ideal e reforçam que os métodos colorimétricos são os mais utilizados para a análise de taninos ${ }^{30,31}$.

Entre os métodos colorimétricos, o método de Folin-Denis é bem reconhecido e largamente usado, mas não faz distinção entre compostos fenólicos e outros materiais redutores ou antioxidantes, como o ácido ascórbico, formando precipitados que interferem na leitura espectrofotométrica ${ }^{32}$. O método Folin-Denis foi aperfeiçoado e modificado para o Folin-Ciocalteau ${ }^{33}$. Estudos realizados para a avaliação de métodos quantitativos nas folhas de coníferas, usando Azul da Prússia e Folin-Ciocalteau, revelaram que esse último apresenta maior sensibilidade, para os polifenóis, usando como solvente acetona $50 \%$. Os autores mostraram, ainda, que o método Azul da Prússia apresentou elevada dependência do tempo de reação, comparado ao Folin-Ciocalteau ${ }^{34}$.

Para quantificar taninos condensados os métodos mais utilizados são o butanol-HCl e o vanilina ${ }^{32,35,36}$. De acordo com Schofield e colaboradores ${ }^{32}$, o método vanilina depende da reação da vanilina com os taninos condensados para formação de complexos coloridos. O sucesso deste ensaio depende do tipo do solvente usado, da concentração e natureza do ácido, do tempo da reação, temperatura e concentração da vanilina. O maior problema para o método vanilina parece ser a reatividade de subunidades de polímeros de taninos, o que caracteriza a falta de especificidade, para taninos condensados $^{32}$. A raiz das dificuldades analíticas está na complexidade e variabilidade das estruturas dos taninos condensados ${ }^{32}$.

Em ensaios colorimétricos, o método mais apropriado para a reação com galotaninos e elagitaninos é o método $\mathrm{KIO}_{3}$, sendo o método Rodanina específico para ésteres de ácido gálico ${ }^{31,37}$. Em espécies de Acer, a reação do reagente- $\mathrm{KIO}_{3}$ produz com galo e elagitaninos um complexo de coloração rosa. Mueller-Harvey ${ }^{31}$ acrescentou que para misturas complexas de taninos este ensaio não é viável por formar uma reação marron antes da rosa e ser extremamente dependente da temperatura e duração da reação. Willis e Allen ${ }^{38}$ introduziram modificações no método $\mathrm{KIO}_{3}$, recomendaram a investigação de um tempo ótimo de reação (dependendo de cada espécie estudada) e que não é necessário o resfriamento das amostras para o teste, como se acreditava. Na Tabela 1 são relacionados os principais métodos para quantificação e determinação de taninos totais, condensados, hidrolisáveis e compostos fenólicos em geral.

Por essas moléculas apresentarem uma grande variabilidade de estruturas, tanto em taninos condensados como hidrolisáveis, alta reatividade de suas subunidades com materiais oxidativos e complexação com macromoléculas, o processo de isolamento, identificação e quantificação torna-se bastante complexo.

\section{Observações ecológicas sobre plantas produtoras de taninos}

O custo com a defesa é um problema para as plantas. Se elas investem pouco, o agressor leva vantagem; se investem muito, os recursos vitais são desperdiçados. Os vegetais defendem-se dos herbívoros por vários caminhos, seja por estruturas convencionais como espinhos ou pêlos urticantes ou ainda por sofisticadas defesas químicas, por ex., os taninos. Todos estes métodos consomem energia e os produtos fotossintéticos são desviados do crescimento ou reprodução em prol da defesa, como observou Moore ${ }^{7}$. Compostos fenólicos em vegetais, principalmente taninos, têm reconhecidamente a função de inibir herbívoros, pois em altas concentrações, frutos, folhas, sementes ou demais tecidos jovens tornamse impalatáveis aos fitófagos e, ainda, combinado a algumas proteínas, estes tecidos resistem fortemente à putrefação ${ }^{39,40}$.

Heil $^{22,23}$ e colaboradores relataram que desde 1995 mais de 200 estudos têm quantificado taninos ou compostos fenólicos, no contexto da defesa vegetal contra herbivoria, onde revelaram relações entre o conteúdo de compostos fenólicos em folhas e o decréscimo do uso das mesmas na alimentação. Curiosamente, os estudos ecológicos em plantas medicinais são escassos, principalmente associando o teor de taninos com variáveis ambientais. Os taninos reagem com enzimas do trato digestivo dos herbívoros. Heldt ${ }^{6}$ citou 
Tabela 1. Sumário de métodos viáveis para quantificação e determinação de taninos (condensados e hidrolisáveis) e compostos fenólicos*

\begin{tabular}{|c|c|c|c|}
\hline Nome do ensaio & Tipo do ensaio & Vantagens & Desvantagens \\
\hline Follin-Ciocalteau & Químico, colorimétrico & Teste para todos os fenóis & $\begin{array}{l}\text { Quimicamente complexo. Reage com todos os } \\
\text { fenóis }\end{array}$ \\
\hline Azul da Prússia & Químico, colorimétrico & Teste para todos os fenóis & $\begin{array}{l}\text { Dependendo de condições, todos os fenóis podem } \\
\text { reagir. Agentes redutores também reagem }\end{array}$ \\
\hline Ácido-butanol & Químico, colorimétrico & $\begin{array}{l}\text { Específico para taninos } \\
\text { condensados }\end{array}$ & $\begin{array}{l}\text { Requer um padrão interno. Produção de cor } \\
\text { variando com a estrutura química }\end{array}$ \\
\hline Vanilina & Químico, colorimétrico & Específico para meta-fenóis & $\begin{array}{l}\text { Mesmas observações para o método ácido-butanol. } \\
\text { Reage também com difenóis simples }\end{array}$ \\
\hline $\mathrm{KIO}_{3}$ & Químico, colorimétrico & $\begin{array}{l}\text { Quantifica galotaninos e } \\
\text { elagitaninos }\end{array}$ & $\begin{array}{l}\text { Não é viável para misturas complexas de taninos. } \\
\text { Desenvolvimento da cor é extremamente depen- } \\
\text { dente da temperatura e duração da reação }\end{array}$ \\
\hline Rodanina & Químico, colorimétrico & $\begin{array}{l}\text { Específico para ésteres de } \\
\text { ácido gálico }\end{array}$ & Não é específico para taninos (galotaninos) \\
\hline $\mathrm{NaNO}_{2}$ & Químico, colorimétrico & Específico para elagitaninos & \\
\hline Enzimático & Inibição enzimática & $\begin{array}{l}\text { Indicado para avaliações } \\
\text { biológicas }\end{array}$ & Algumas enzimas são mais suscetíveis que outras \\
\hline $\begin{array}{l}\text { Precipitação de } \\
\text { proteínas }\end{array}$ & Precipitação & $\begin{array}{l}\text { Reflete um importante } \\
\text { processo biológico }\end{array}$ & $\begin{array}{l}\text { Resultado dependendo de muitas variáveis, como a } \\
\text { escolha da proteína }\end{array}$ \\
\hline HPLC & HPLC & $\begin{array}{l}\text { Para polímeros acima de } \\
7-8 \text { unidades }\end{array}$ & $\begin{array}{l}\text { Alguns taninos condensados ligam-se } \\
\text { irreversivelmente }\end{array}$ \\
\hline $\begin{array}{l}\text { Inibição de crescimento } \\
\text { microbiano }\end{array}$ & Toxicológico & Bom ensaio biológico & $\begin{array}{l}\text { Escolha de bactéria e composição do meio podem } \\
\text { afetar os resultados }\end{array}$ \\
\hline Tiólise & Químico, HPLC & $\begin{array}{l}\text { Bom para determinar } \\
\text { estruturas }\end{array}$ & Requer taninos puros \\
\hline Precipitação por Ytérbio & Gravimétrico & Não precisa de padrão & Rendimento pode variar com a proporção $\mathrm{Yb}$ :tanino \\
\hline
\end{tabular}

* modificado das refs. 31 e 32, com permissão da Elsevier.

um exemplo que ocorre nas savanas sulafricanas, onde folhas de acácia são recursos alimentares do antílope $k u d u$. Essas folhas contêm taninos que, em baixas quantidades, não afetam sua qualidade nutricional. Quando estas árvores são predadas pelos antílopes, liberam o etileno, hormônio vegetal que induzirá, em cerca de 30 min, o aumento da síntese de taninos em árvores vizinhas. $\mathrm{O}$ autor relatou que os níveis aumentam de tal maneira que os mamíferos podem chegar à morte se continuarem a alimentar-se dessas folhas. Embora esteja bem conhecido o potencial antinutricional dos taninos, algumas plantas e animais usam estratégias para reduzir a adstringência causada por estes compostos ${ }^{4}$. Em frutos, observou o autor, a redução da adstringência não parece ser devido à diminuição das quantidades de taninos e sim pela produção de moléculas com afinidade por estes. Alguns animais, como ratos, que possuem uma dieta rica em taninos conseguem induzir uma liberação maior de proteínas salivares para, assim, se protegerem contra o efeito da adstringência, relatou Scalbert ${ }^{4}$.

Alguns estudos sobre variações do teor de taninos mostram que há diferenças quando as plantas são coletadas e analisadas em períodos distintos ${ }^{13,15,41-45}$. Polifenóis de baixo peso molecular e elagitaninos foram analisados em HPLC, por Simon e colaboradores $^{15}$, em quatro espécies de carvalho (Quercus robus L., $Q$. petraea Liebl., $Q$. pyrenaica Wild. e $Q$. faginea Lam.) obtidos do extrato da madeira. As coletas foram realizadas antes e depois de um ano e, durante este processo, as concentrações de polifenóis de baixo peso molecular aumentaram e a concentração de elagitaninos, dímeros e monômeros, diminuíram. Os autores concluíram que a sazonalidade natural afeta a composição química devido a processos de desidratação e maturação. As modificações químicas foram similares nas quatro espécies.

Hatano e colaboradores ${ }^{41}$ relataram diferenças nas concentrações de telimagrandina II (tanino hidrolisável) em Liquidambar formosana Hance de acordo com as estações anuais. No início da primavera, este composto rapidamente decresce dentro de um mês, sendo negligenciável a quantidade presente no verão. Entretanto, as quantidades de casuarinina e pedunculaginina (taninos hidrolisáveis) aumentaram com o tempo, sendo significativas no verão e outono. Estes resultados retrataram perfis de rotas biogenéticas distintas para a formação de compostos fenólicos.

Salminen e colaboradores ${ }^{42}$ pesquisaram a variação sazonal de taninos hidrolisáveis em folhas de Betula pubescens Ehrh., associados a herbivoria. O nível máximo de compostos fenólicos foi encontrado em folhas jovens e, durante a maturação, o conteúdo decresce rapidamente. Os autores evidenciaram que os taninos hidrolisáveis apresentam padrões de sazonalidade distintos e as variações de galoilglucose e elagitaninos são diferentes por apresentarem caminhos biossintéticos distintos.

A quantificação mensal de taninos condensados durante dois anos em Plumbago scandens L. e P. auriculata Lam. mostrou, respectivamente, baixa e elevadas concentrações ${ }^{43}$. Em 2001, a concentração de taninos condensados foi superior ao ano anterior em P. auriculata Lam. Os autores evidenciaram que as duas espécies foram cultivadas em horto e $P$. auriculata Lam. foi mantida em solo não preparado, sendo pobre em nutrientes e ainda foram realizadas podas regulares. $P$. scandens L. teve condições hídricas favoráveis e solo devidamente adubado. Tais influências, concluíram os autores, podem ser responsáveis pela variabilidade dos teores entre as espécies.

Os efeitos da poluição na atmosfera podem alterar a resistência de Tibouchina pulchra Cogn. à herbivoria. O estudo de duas localidades no Sudoeste do Brasil mostrou que as altas taxas de poluição atmosférica induzem ao aumento da quantidade de nitrogênio foliar e ao decréscimo de compostos fenólicos nas folhas, devido, provavelmente, ao baixo ganho de carbono ${ }^{44}$. 


\section{Atividade biológica dos taninos}

As aplicações de drogas com taninos estão relacionadas, principalmente, com suas propriedades adstringentes. Por via interna exercem efeito antidiarréico e anti-séptico; por via externa impermeabilizam as camadas mais expostas da pele e mucosas, protegendo assim as camadas subjacentes ${ }^{3}$. Ao precipitar proteínas, os taninos propiciam um efeito antimicrobiano e antifúngico. Ademais, os taninos são hemostáticos e, como precipitam alcalóides, podem servir de antídoto em casos de intoxicações ${ }^{3}$. Em processos de cura de feridas, queimaduras e inflamações, os taninos auxiliam formando uma camada protetora (complexo tanino-proteína e/ ou polissacarídeo) sobre tecidos epiteliais lesionados, podendo, logo abaixo dessa camada, o processo curativo ocorrer naturalmente ${ }^{2}$.

Provavelmente, devido à habilidade de ligar-se às proteínas e outras macromoléculas, os taninos também apresentam atividades tóxicas. Ayres e colaboradores ${ }^{46}$ verificaram que a rápida mortalidade de insetos tratados com taninos condensados parece ser devido à atividade tóxica destes compostos e não pela inibição da digestibilidade. Elagitaninos dímeros são mais adstringentes que os monômeros ${ }^{4}$. Deste modo, se a toxicidade é devido a sua adstringência, alta toxicidade está intimamente associada ao maior peso da molécula. Contudo, isto não ocorre sempre, por ex., a catequina apresenta maior toxicidade que os taninos, embora esta tenha pouca afinidade por proteínas ${ }^{4,47,48}$. Um outro mecanismo de toxicidade, que pode envolver os taninos, deve-se ao fato desses complexarem-se com facilidade a íons metálicos. Sistemas biológicos, incluindo microrganismos, necessitam de íons metálicos como cofatores enzimáticos. Por ex., ratos tratados com bebidas ricas em compostos fenólicos tiveram redução da absorção de ferro ${ }^{4}$.

Os taninos são considerados nutricionalmente indesejáveis porque precipitam proteínas, inibem enzimas digestivas e afetam a utilização de vitaminas e minerais podendo, ainda, em alta concentração, desenvolver câncer de bochecha e esôfago, ${ }^{9,49-51}$. Acredita-se que altos teores de taninos ingeridos por animais domésticos, em alimentos como sorgo ou farinha de sementes de uva, podem levar à morte. Chung e colaboradores ${ }^{9,49}$ relataram que nozes contendo cerca de $25 \%$ de taninos podem ser responsáveis pela alta incidência de câncer de esôfago em uma determinada localidade dos EUA, onde pessoas comumente as consomem após o almoço. Contraditoriamente, a atividade anticarcinogênica é evidenciada pelos mesmos autores, onde afirmam que os japoneses consomem o chá verde, rico em ácido tânico e outros polifenóis, em grandes quantidades e o risco de câncer gástrico mostra-se baixo.

Várias doenças degenerativas como câncer, esclerose múltipla, arteroesclerose e o próprio processo de envelhecimento estão associados a altas concentrações intercelulares de radicais livres. Estudos recentes mostram que vários taninos atuam como captadores de radicais, os quais interceptam o oxigênio ativo formando radicais estáveis ${ }^{2}$. Chung e colaboradores ${ }^{9}$ sugerem que os taninos parecem ter duplo efeito, por um lado, beneficiam a saúde devido a seu efeito quimiopreventivo contra carcinogênese ou atividades antimicrobianas, por outro lado, estão envolvidos possivelmente na formação de cânceres, hepatotoxicidade ou efeitos antinutricionais. Taninos das espécies Quercus suber L. e Q. coccifera L. apresentaram efeito gastroprotetor, variando entre 66 e $91 \%{ }^{52}$.

As propriedades antimicrobianas dos taninos são bem conhecidas e documentadas. Moléculas de taninos estão sendo testadas com a intenção de se descobrir uma droga eficiente contra o HIV $^{9,10,49}$. Kilkuskie e colaboradores ${ }^{10}$ observaram que galotaninos mostraram atividade inibitória somente em concentrações tóxicas, elagitaninos e taninos condensados inibiram fracamente a replicação viral e os taninos complexos mostraram potente atividade contra a replicação do HIV. Concluíram que a atividade anti-HIV exibida por taninos é devida à inibição da transcriptase reversa, dificultando assim a replicação viral.

Uma série de bactérias são sensíveis aos taninos, dentre elas Staphylococcus aureus, Streptococcus pneumonia, Bacillus anthracis e Shigella dysenteriae e, em concentrações mínimas $(0,5 \mathrm{~g} / \mathrm{L})$, o fungo Fomes annosus teve seu crescimento inibido ${ }^{50}$. Nishizawa e colaboradores ${ }^{53}$ demonstraram significante atividade bactericida do decocto da raiz de Nuphar variegatum Durand contra microorganismos patógenos. Em sua revisão, relataram que, por séculos, o rizoma e as raízes desta erva aquática têm sido usados na medicina popular por suas propriedades afrodisíacas, hemostáticas, adstringentes e sedativas. O rizoma, em especial, é empregado na cura de infecções diversas e o decocto da raiz para tratamento de infecções dos olhos, garganta e dores internas. A análise cromatográfica (HPLC) do extrato aquoso da raiz desta planta evidenciou dois galotaninos e dois elagitaninos, sendo reconhecidos por nupharina A e nupharina B. Scalbert ${ }^{4}$ relata que taninos condensados e hidrolisáveis não apresentam diferenças significantes frente a fungos e bactérias, visto que o efeito da toxicidade relacionado à estrutura molecular do tanino é ainda desconhecido.

\section{CONSIDERAÇÕES FINAIS}

Evolutivamente as plantas tendem a sintetizar compostos, subprodutos do seu metabolismo primário, para diversas aplicações, como atrativos de polinizadores ou inibidores de fitófagos. Os elementos do metabolismo especial, que um dia foram considerados como resíduos ineficazes dos produtos fotossintéticos e respiratórios, hoje ganham reconhecimento e investimentos cada vez maiores para implantação de pesquisas. Inclusos nesse metabolismo, os taninos mostram-se extremamente promissores e podem ser estudados através de técnicas quantitativas relativamente fáceis e de baixo custo.

A grande diversidade de estruturas dos compostos tânicos que são encontradas em plantas com reconhecidas atividades terapêuticas, associada a sua capacidade de complexação com diferentes compostos, torna o trabalho de elucidação estrutural difícil ${ }^{54}$. Apesar de várias pesquisas realizadas sob diferentes abordagens com teores de taninos, a associação dessas informações com o aproveitamento de plantas medicinais é escassa. As seguintes abordagens merecem ser exploradas com mais profundidade: influência da sazonalidade e do local de coleta; efeito da poluição atmosférica; efeito da restrição de nutrientes no solo; alternativas para obtenção de taninos de espécies arbóreas (comparação dos teores com ervas, por ex.); comparação dos teores de taninos entre partes da mesma planta, visando orientar uma extração mais sustentável e correlação entre os teores de taninos e atividade biológica (antimicrobiana, por ex.).

\section{REFERÊNCIAS}

1. Sant'ana, A. E. G. Em Biodiversidade, Conservação e Uso Sustentável da Flora do Brasil; Araújo, E. L.; Moura, A. N.; Sampaio, E. S. B.; Gestinari, L. M. S.; Carneiro, J. M. T., eds.; Imprensa Universitária: UFRPE, Recife, 2002.

2. Mello, J. P. C.; Santos, S. C. Em Farmacognosia: da planta ao medicamento; Simões, C. M. O.; Schenckel, E. P., orgs.; Ed. UFSC: Porto Alegre; $3^{\mathrm{a}}$ ed., 2001.

3. Bruneton, J.; Elementos de Fitoquímica y de Farmacognosia, Ed. Acribia, SA: Espanha, 1991.

4. Scalbert, A.; Phytochemistry 1991, 30, 3875

5. Mole, S.; Roglers, J. C.; Butler, L. G.; Biochem. Syst. Ecol. 1993, $21,667$.

6. Heldt, H.; Plant Biochemistry and Molecular Biology, University Press: Oxford, 1997. 
7. Moore, P. D.; Nature 1998, 39, 838.

8. Paes, J. B.; Moraes, V. M.; Lima, C. R.; Floresta e Ambiente 2002, 9, 135.

9. Chung, K.; Wei, C.; Johnson, M. G.; Trends Food Sci. Technol. 1998, 9, 168.

10. Kilkuskie, R. E.; Kashiwada, Y.; Nonaka, G.; Nishioka, I.; Bodner, A.; Cheng, Y.; Lee, K.; Bioorg. Med. Chem. Lett. 1992, 2, 1529.

11. Rodrigues, W. A.; Paiva, E.; Santos, G. F.; Rodrigues, J. A. S.; Ciência Prática de Lavras 1992, 16, 74.

12. Magalhães, P. C.; Rodrigues, W. A.; Durães, F. O. M.; Circular Técnica 1997, 27.

13. Teixeira, M. L.; Soares, A. R.; Scolforo, J. R. S.; Ciência Prática de Lavras 1990, 14, 229.

14. Caldeira, M. V. W.; Schumacher, M. V.; Santos, E. M.; Viegas, J.; Pereira, J. C.; Boletim de Pesquisas Florestais 1998, 37, 81.

15. Simón, B. F.; Cadahia, E.; Conde, E.; J. Agric. Food Chem. 1999, 47, 1687.

16. Haslam, E.; Phytochemistry 1965, 4, 495

17. Haslam, E.; J. Chem. Ecol. 1988, 14, 1789.

18. Bianco, M. A.; Savolainen, H.; Sci. Total Environ. 1997, 203, 79.

19. Vickery, M. L. E.; Vickery, B.; Secondary Plant Metabolism, The Macmillan Press LTD: London, 1981.

20. Brandes, D.; Freitas, E. A. G.; Agropecuária Catarinense 1992, 5, 44.

21. De Bruyne, T.; Pieters, L.; Deelstra, H.; Vlietinck, A.; Biochem. Syst. Ecol. 1999, 27, 445 .

22. Heil, M.; Baumann, B.; Andary, C.; Linsenmair, K. E.; Mckey, D.; Naturwissenschaften 2002, 89, 519.

23. Heil, M.; Delsinne, T.; Hilpert, A.; Schürkens, S.; Andary, C.; Linsenmair, E. K.; Sousa, M.; McKey, D.; Oikos 2002, 99, 457.

24. Grundhöfer, P.; Gross, G. G.; Plant Sci. 2001, 160, 987.

25. Grundhöfer, P.; Niemetz, R.; Schilling, G.; Gross, G. G.; Phytochemistry 2001, 57, 915 .

26. Mole, S.; Biochem. Syst. Ecol. 1993, 21, 833.

27. Santos, D. M.; Blatt, C. T. T.; Rev. Bras. Bot. 1998, 21, 135.

28. Hagerman, A. E.; Butler, L. G.; J. Chem. Ecol. 1989, 15, 1795.

29. Hagerman, A. E.; Zhao, Y.; Johnson, S.; Antinutrients and Phytochemicals in Food 1997, 12, 209.

30. Mondal, K. C.; Banerjee, D.; Jana, M.; Pati, B. R.; Anal. Biochem. 2001, 295,168 .

31. Mueller-Harvey, I.; Animal Feed Science and Technology 2001, 91, 3.

32. Schofield, P.; Pell, A. N.; Mbugua, D. M.; Animal Feed Science and Technology 2001, 91, 21.
33. Folin, O.; Ciocalteau, V.; J. Biol. Chem.1927, 73, 424

34. Dahlgren, A.; Yu, Z.; J. Chem. Ecol. 2000, 26, 2119.

35. Morais, S. A. L.; Nascimento, E. A.; Queiroz, C. R. A. A.; J. Braz. Chem. Soc. 1999, 10, 447.

36. Agostini-Costa, T. S.; Lima, A.; Lima, M. V.; Quim. Nova 2003, 26, 763.

37. Wilson, T. C.; Hagerman, A. E.; J. Agric. Food Chem. 1990, 38, 1678

38. Willis, R. B.; Allen, P. R.; Analyst 1998, 123, 435.

39. Smith, P. M.; The Chemotaxonomy of Plants, Edward Arnold (Publishers) Limited.: England. 1976.

40. Volz, T. J.; Clausen, T. P.; J. Chem. Ecol. 2001, 27, 725.

41. Hatano, T.; Kira, R.; Yoshizaki, M.; Okuda, T.; Phytochemistry 1986, 25 , 2787.

42. Salminen, J.; Ossipov, V.; Haukioja, E.; Pihlaja, K.; Phytochemistry 2001, 57, 15.

43. Paiva, S. R.; Heringer, A. P.; Figueredo, M. R.; Kaplan, M. A. C.; Floresta e Ambiente 2002, 9, 153.

44. Furlan, C. M.; Domingos, M.; Salatino, A.; Rev. Bras. Bot. 1999, 22, 317.

45. Pansera, M. R.; Santos, A. C. A.; Paese, K.; Wasum, R.; Rossato, M.; Rota, L. D.; Pauletti, G. F.; Serafini, L. A.; Revista Brasileira de Farmacognosia 2003, 13, 17.

46. Ayres, M. P.; Clausen, T. P.; Maclean, S. F.; Redman, A. M.; Reichardt, P. B.; Ecology 1997, 78, 1696.

47. Itakura, Y.; Habermehl, G.; Mebs, R.; Toxicon 1987, 25, 1291.

48. Aguilar-Ortigoza, C. J.; Soza, V.; Aguilar-Ortigoza, M.; Econ. Botany 2003 , $5,354$.

49. Chung, K.; Wong, T. Y.; Wei, C.; Huang, Y.; Lin, Y.; Crit. Rev. Food Sci. Nutrition 1998, 38, 421.

50. Castro, H. G.; Casali, V. W. D.; Barbosa, L. C. A.; Cecon, P. R.; Revista Brasileira de Plantas Medicinais 1999, 1, 29.

51. Singh, B.; Bhat, T. K.; Sharma, O. P.; Livestok Production Science 2001, $68,259$.

52. Khennouf, S.; Benabdallah, H.; Gharzouli, K.; Amira, S.; Ito, N.; Kim, T.; Yoshida, T.; Gharzouli, A.; J. Agric. Food Chem. 2003, 51, 1469.

53. Nishizawa, K.; Nakata, I.; Kishida, A.; Ayer, W. A.; Browne, L. M.; Phytochemistry 1990, 29, 2491.

54. Okuda, T.; Yoshida, T.; Hatano, M. I.; Kubo, M.; Orime, T.; Yoshizaqui, M.; Naruhashi, N.; Phytochemistry 1992, 31, 3091. 